\title{
Monitoring of free glutamic acid in Malaysian processed foods, dishes and condiments.
}

\begin{abstract}
A study to quantify the free glutamic acid content of six processed foods, 44 dishes and 26 condiments available in Malaysia was performed using high-performance liquid chromatography with a fluorescence detector (HPLC-FRD). Recovery tests were carried out with spiked samples at levels from 6 to $31 \mathrm{mg} \mathrm{g}-1$. High recovery in different matrices was achieved ranging from $88 \% \pm 13 \%$ to $102 \% \pm 5.12 \%$, with an average of $97 \% \pm 8.92 \%$. Results from the study revealed that the average free glutamic acid content ranged from 0.34 \pm 0.20 to $4.63 \pm 0.41 \mathrm{mg} \mathrm{g}-1$ in processed foods, while in prepared dishes it was as low as $0.24 \pm 0.15 \mathrm{mg} \mathrm{g}-1$ in roti canai (puffed bread served with curry or dhal) to $8.16 \pm 1.99 \mathrm{mg}$ g-1 in dim sum (a small casing of dough, usually filled with minced meat, seafood, and vegetables, either steamed or fried). Relatively, the content of free glutamic acid was found to be higher in condiments at $0.28 \pm 0 \mathrm{mg} \mathrm{g}-1$ in mayonnaise to $170.90 \pm 6.40 \mathrm{mg} \mathrm{g}-1$ in chicken stock powder.
\end{abstract}

Keyword: Free glutamic acid; Processed food; Dish; Condiments; High-performance liquid chromatography (HPLC). 